\title{
4. Results
}

\section{I Section I: Trends in the number of children and adolescents treated with stimulant medication for the first time}

\section{I.I Overall trend}

Figure 1 shows the number of children with ADHD who were commenced on stimulant medication for the first time in each year in the period 1990 to 2000. It can be seen that a significant increase occurred over this time, particularly in the period 1990 to 1994. The slight downward change from 1995 to 1996 may, at least in part, be due to the introduction of the general approval system. The number of children commenced on stimulant medication for the first time in 2000 was about five times the number for 1990.

\subsubsection{Age at commencement}

Figure 2 shows the number of children with ADHD who were commenced on stimulant medication for the first time in the period 1990 to 2000 according to the age of the child at commencement of stimulant treatment.

For all age groups there was an upward trend in the number of children commenced on stimulant medication for the first time in the period 1990 to 2000. For the largest group of children, 7-11 year olds, the number commenced on stimulant treatment for the first time in 2000 was 4.4 times higher than the number in 1990. The increase for children aged less than four years was similar at 4.8 times. These increases were similar to the overall average (4.8 times). For children in the age group 12-15 years, the increase (3.5 times) was slightly lower than the average.

The other age groups evidenced a somewhat greater increase, with children aged four years having the greatest increase at nine times. Most of the increase among children

Number of children with ADHD commenced on stimulant medication for the first time by year of commencement, 1990 to 2000

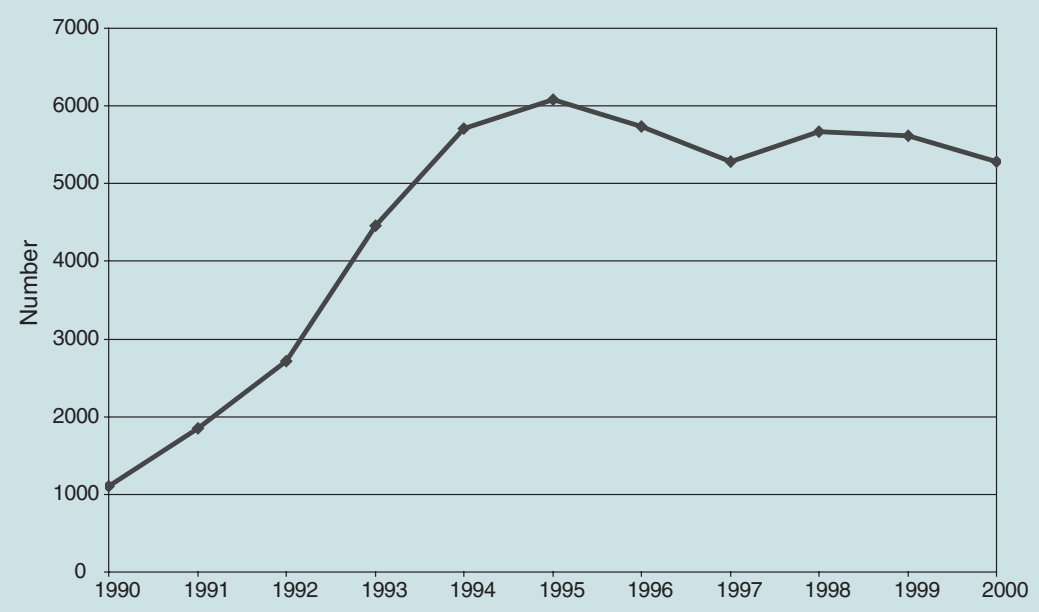

Source: Pharmaceutical Drugs of Addiction System, Pharmaceutical Services Branch, NSW Department of Health. 
aged less than four years was due to an increase in the number of three year olds starting stimulant treatment for the first time. For children aged 5-6 years the number started on stimulant medication for the first time in 2000 was seven times higher than the number in 1990. For children aged 16-17 years the increase was 7.6 times.

Although relatively young children and children in their late teens had the greatest increases from 1990 to 2000, the increase in the absolute number of children in these age groups was quite small. For example, the number of children aged less than four years who were commenced on stimulant treatment for the first time in 1990 was 18, while the comparable number for 2000 was 86 . For 16-17 year olds the number went from 27 in 1990 to 205 in 2000.

Figure 3 illustrates how the mix of children commenced on stimulant medication for the treatment of ADHD changed over the period 1990 to 2000. It shows the number of children who commenced stimulant treatment for the first time in the period 1990 to 2000 by age group, as a percentage of all children who started stimulant treatment for the first time. The age group 7-11 years is split into 7-8 year olds and 9-11 year olds because these groups had slightly different trends.

Over the period 1990 to 2000 , very young children and older teenagers have consistently comprised a small proportion of all children commenced on stimulant medication for the first time. Their representation, however, over this time has gradually increased. Similarly, the representation of children aged 5-6 years among children commencing stimulant treatment for the first time has increased. Conversely, the proportion of children commenced on stimulant medication for the first time aged 9-15 years has gradually decreased.

There has been a slight downtrend in the average age of children who commenced stimulant treatment for the first time over the period 1990 to 2000. In 1990 the average age of children first started on stimulant medication was 9.4 years $(\mathrm{SD}=3.0$ years). In 2000 it was 8.8 years $(\mathrm{SD}=3.3$ years $)$.

\section{FIGURE 2}

\section{Number of children with ADHD commenced on stimulant medication for the first time, by age and year at commencement, 1990 to 2000}

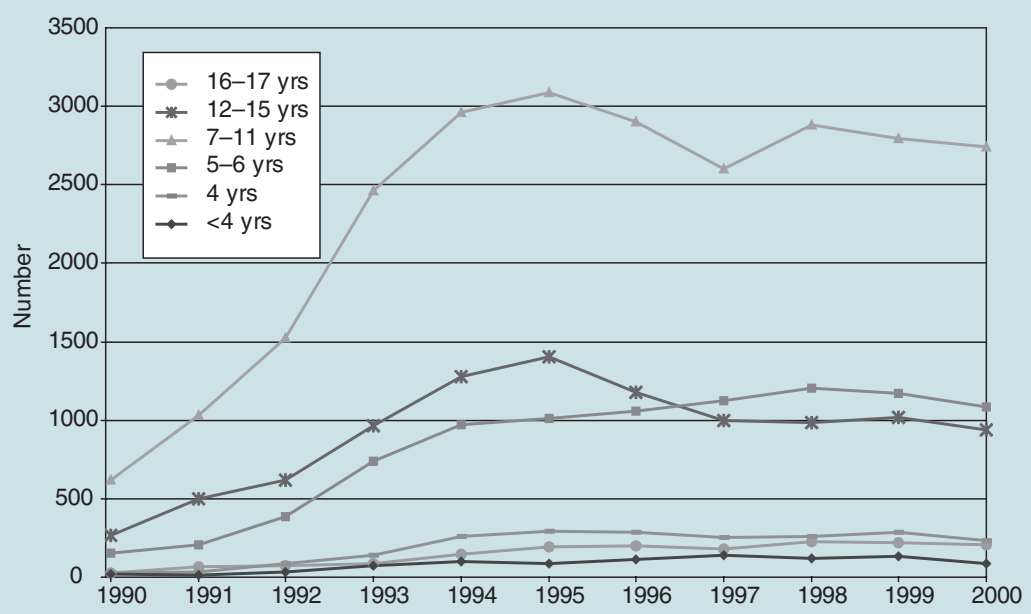

Source: Pharmaceutical Drugs of Addiction System, Pharmaceutical Services Branch, NSW Department of Health. 


\subsubsection{Sex}

Figure 4 shows the number of children with ADHD who were commenced on stimulant medication for the first time in each year in the period 1990 to 2000 by sex. Although the majority of children started on stimulant medication for the first time have been male, the growth in the number of females commenced on medication has been greater than the growth in the number of males. From 1990 to 2000, the number of girls commenced on stimulant medication increased by 6.5 times; the increase for boys was 4.4 times. Thus, there has been a slight downward trend in the proportion of children first commenced on stimulant medication who are male. In 1990 the proportion of children who were male was 84.1 per cent. In 1999 the figure was 78.5 per cent.

This downward trend in the proportion of children first started on stimulant medication who were male occurred across all age groups.

\subsubsection{Drug}

Figure 5 shows the number of children with ADHD who were commenced on stimulant medication for the first time in the period 1990 to 2000 according to the drug used for treatment. The initial drug used could not be determined for a large number of children in 1996 therefore data for 1996 are missing from Figure 5. For other years in the period 1994 to 2000 , a small number of children are excluded for whom the initial drug used could not be determined.

Since 1993, a larger number of children started on stimulant medication for the first time have been initially treated with dexamphetamine rather than methylphenidate. In 2000, 56 per cent of children who started stimulant medication for the first time were commenced on dexamphetamine.

\section{FIGURE 3}

Per cent of children with ADHD commenced on stimulant medication for the first time, by age and year at commencement, 1990 to 2000

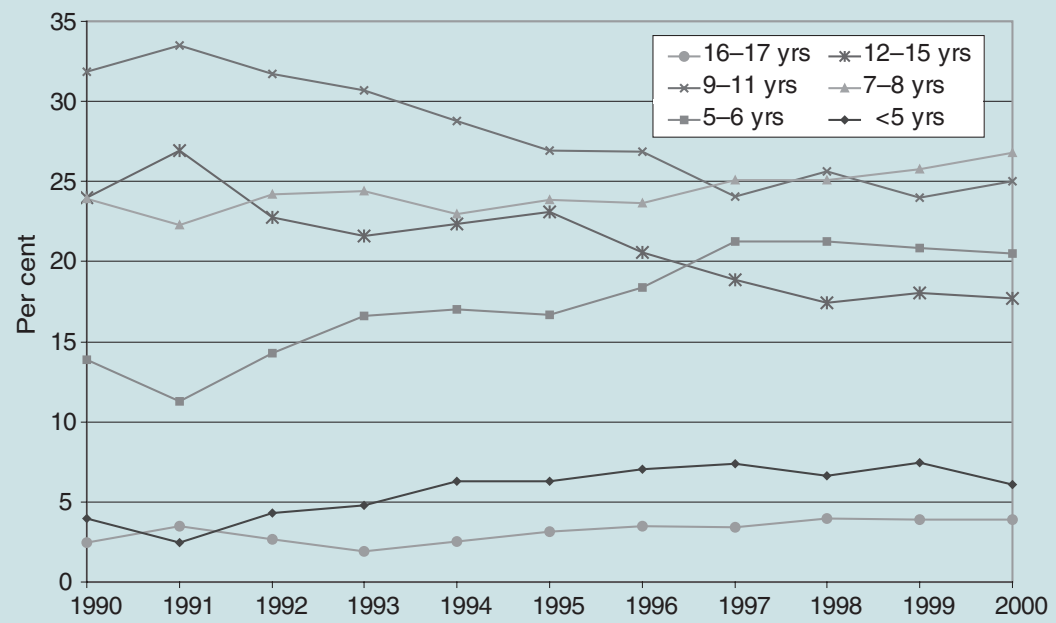

Source: Pharmaceutical Drugs of Addiction System, Pharmaceutical Services Branch, NSW Department of Health. 


\section{Number of children with ADHD commenced on stimulant medication for the first time by sex, 1990 to 2000}

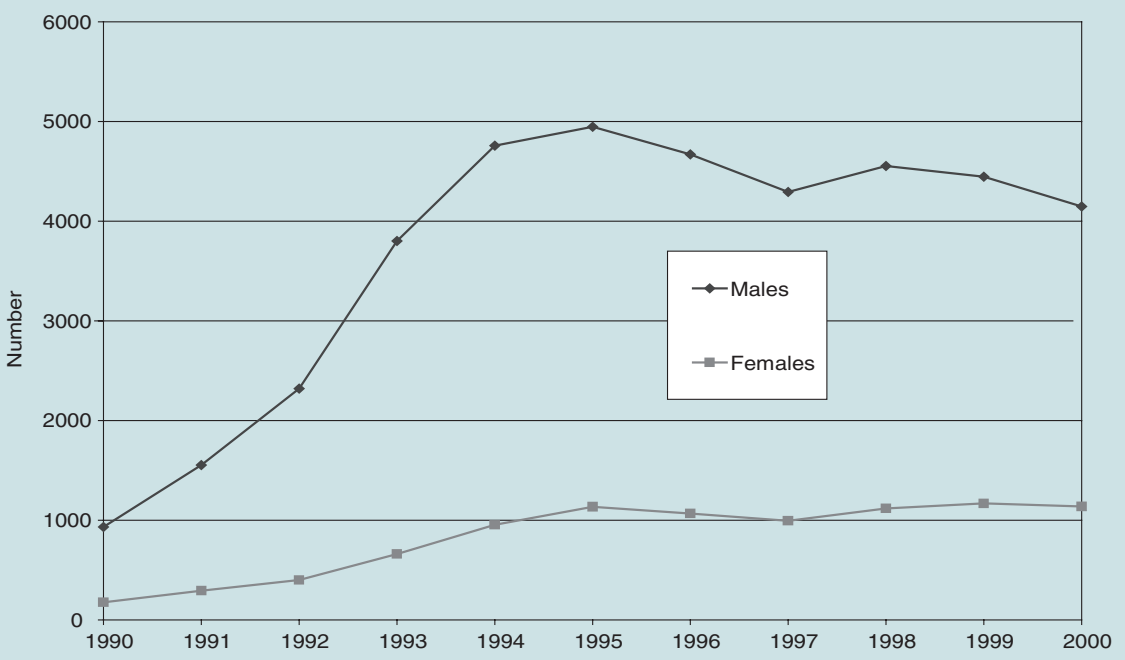

Note: Data for 1990 excludes one child whose sex was unknown.

Source: Pharmaceutical Drugs of Addiction System, Pharmaceutical Services Branch, NSW Department of Health.

\section{FIGURE 5}

Number of children with ADHD commenced on stimulant medication for the first time, by drug and year at commencement, 1990 to 2000

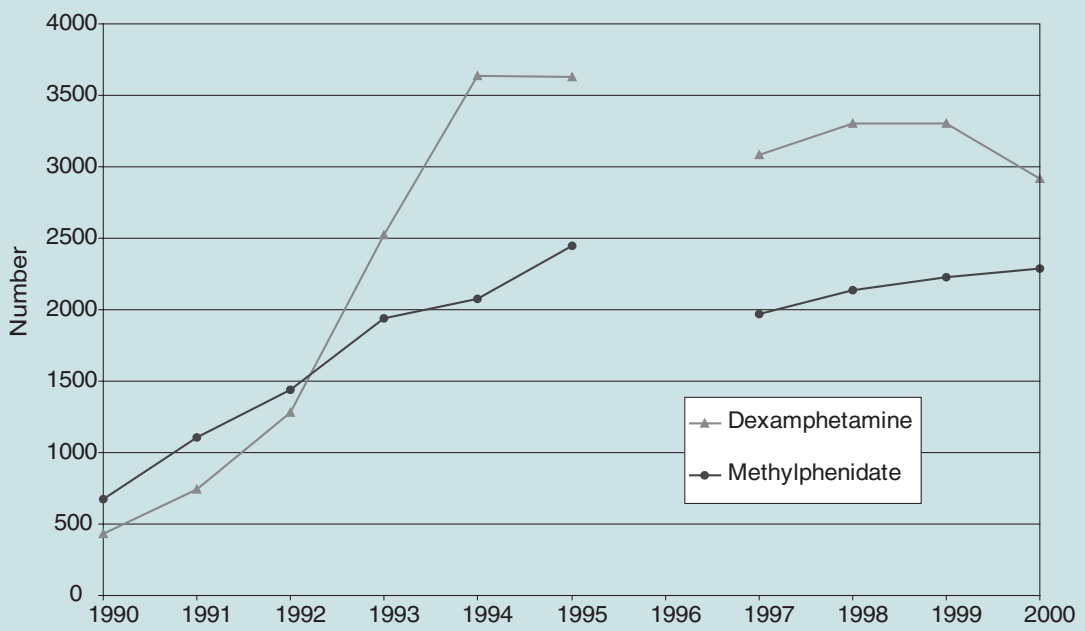

Note: The initial drug used could not be determined for a large number of children first treated with stimulant medication in 1996, therefore data for 1996 are not shown. For the other years in the period 1994 to 2000, a small number of children are excluded for whom the initial drug used could not be determined.

Source: Pharmaceutical Drugs of Addiction System, Pharmaceutical Services Branch, NSW Department of Health. 


\subsection{Section 2: Trends in the rate of children and adolescents treated with stimulant medication}

\subsection{Sex}

Figure 6 shows the number of children with ADHD per 1,000 NSW resident population aged 2-17 years who were treated with stimulant medication as at 30 June of each year in the period 1990 to 2000. Separate trends for males, females, and all children are presented.

It can be seen that there was a sharp increase in the rate of children on stimulant medication after 1993. From 1996 to 2000 the rate has been fairly stable. It should be noted that a change in the approval system to prescribe stimulant medication occurred in NSW in 1996.

Overall, from 1990 to 2000, there was a nine-fold increase in the rate of children treated with stimulant medication for ADHD. The increase for girls (10.8 times) was slightly greater than the increase evidenced for boys ( 8.8 times).

\subsubsection{Age}

Figure 7 shows the number of children with ADHD per 1,000 NSW resident population who were treated with stimulant medication as at 30 June of each year in the period 1990 to 2000 by age.

It can be seen that all age groups experienced an increase over the period 1990 to 2000. For two groups of children the increase in the rate from 1990 to 2000 was higher than the average increase (9.1 times); children in the age group 5-6 years (increase of 10.8 times) and children in the age group 16-17 years (increase of 14 times). For children in the age group 7-11 years, the rate increased 8.9 times from 1990 to 2000. For children in the age group 12-15 years the rate increased 8.1 times, while for children aged less than five years the increase in the rate was 7.5 times.

Although not shown here, the trends for male and female children were generally similar to the trend for all children. A notable exception was for female children aged 16-17 years. For this group, the rate from 1990 to 2000 increased about 27 times, going from a rate of 0.1 to a rate of 2.7 (per 1,000 females aged 16-17 years).

The average age of children on stimulant medication as at 30 June was fairly stable over the period 1990 to 2000 , at around 11 years of age.

\subsubsection{Drug}

Figure 8 shows the number of children with ADHD per 1,000 NSW resident population aged 2-17 years who were treated with stimulant medication as at 30 June of each year in the period 1990 to 2000 by drug used for treatment. The drug used could not be determined for a large number of children in 1996 therefore data for 1996 are missing from Figure 8. For other years in the period 1995 to 2000, a small number of children are excluded for whom the drug used could not be determined.

From 1990 to 1993, slightly more children on stimulant medication were on methylphenidate than were on dexamphetamine. For most other years in the period 1990 to 2000, the number of children on dexamphetamine was about the same as the number on methylphenidate.

Although not shown here, the trends for male and female children were similar to the 
Rate per I,000 NSW resident population of children treated with stimulant medication for ADHD by sex and year, 30 June, 1990 to 2000

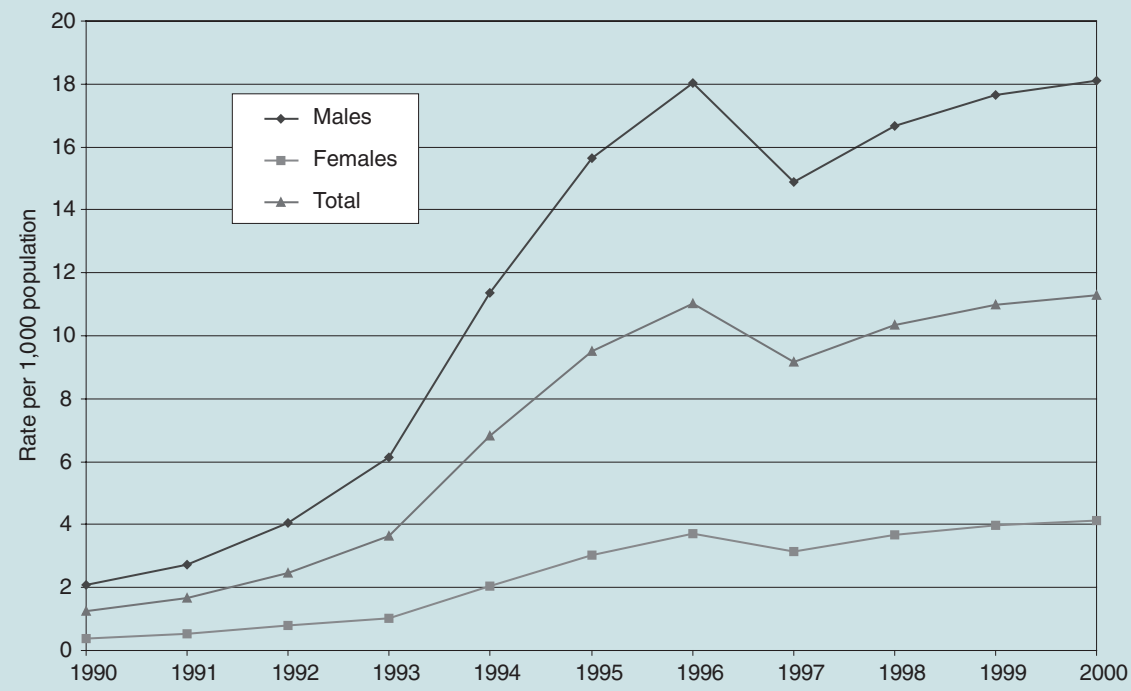

Notes: NSW resident population based on Australian Bureau of Statistics preliminary estimates of population as at 30 June 2000 (Catalogue no. 3201.0).

The total for 1990 includes one person whose sex was unknown.

Source: Pharmaceutical Drugs of Addiction System, Pharmaceutical Services Branch, NSW Department of Health.

\section{FIGURE 7}

Rate per I,000 NSW resident population of children treated with stimulant medication for ADHD by age and year, 30 June, 1990 to 2000

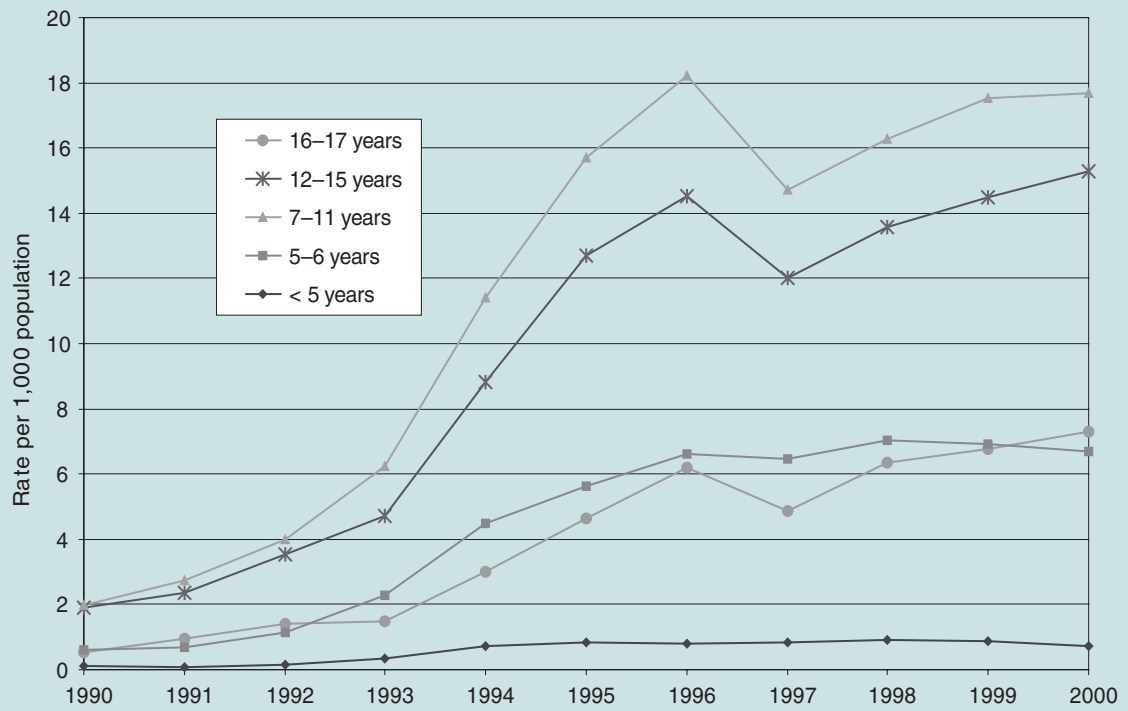

Note: NSW resident population based on Australian Bureau of Statistics estimates of population as at 30 June (Catalogue no. 3201.0).

Source: Pharmaceutical Drugs of Addiction System, Pharmaceutical Services Branch, NSW Department of Health. 
FIGURE 8

Rate per I,000 NSW resident population of children treated with stimulant medication for ADHD by drug and year, 30 June, 1990 to 2000

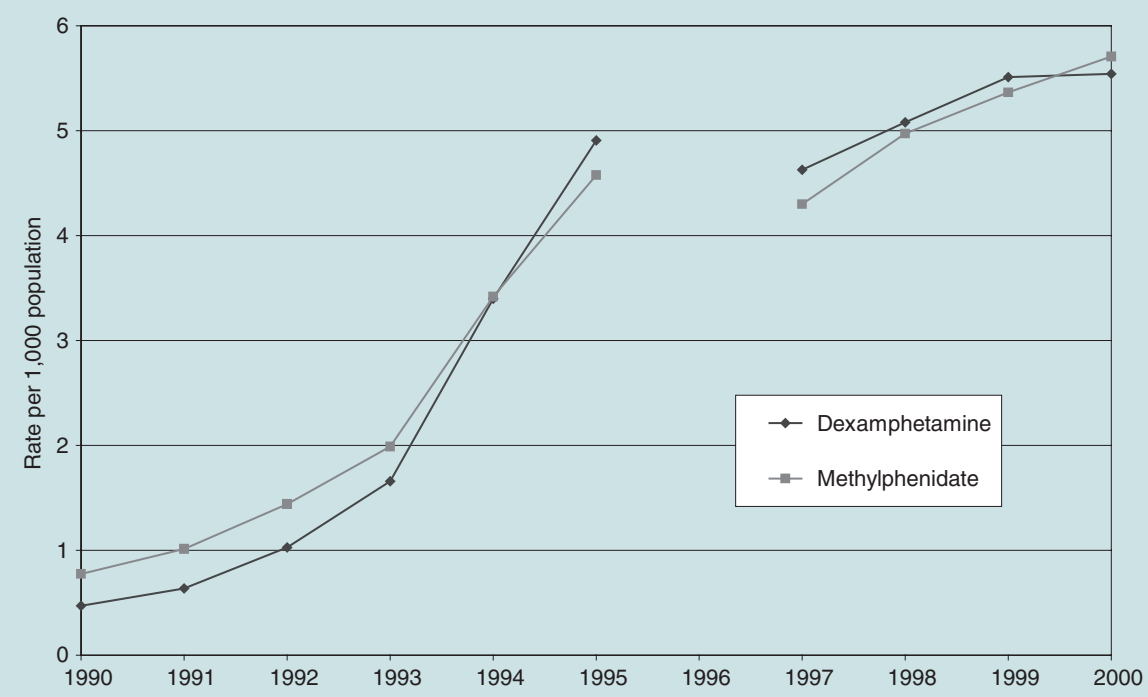

Note: The drug used could not be determined for a large number of children treated with stimulant medication as at 30 June 1996, therefore data for 1996 are not shown. For the other years in the period 1995 to 2000, a small number of children are excluded for whom the drug used could not be determined.

NSW resident population based on Australian Bureau of Statistics estimates of population as at 30 June (Catalogue no. 3201.0)

Source: Pharmaceutical Drugs of Addiction System, Pharmaceutical Services Branch, NSW Department of Health.

trend for all children. 


\subsection{Section 3: Characteristics of children and adolescents treated with stimulant medication}

\subsection{Age and Sex}

Table 1 shows the age and sex breakdown of children who were being treated with stimulant medication for ADHD as at 1 December 2000. It also shows the ratio of male children to female children.

From Table 1 it can be seen that the age distribution for boys was similar to that for girls. For almost every age group, boys outnumbered girls by between four and five times. Among three-year olds, boys outnumbered girls almost eight to one.

The average age of children on stimulant medication as at 1 December 2000 was 10.8 years $(\mathrm{SD}=3.1$ years $)$.

Table 2 shows the number and rate of children treated with stimulant medication for ADHD as at 1 December 2000 by sex. The rate is based on the estimated number of children in NSW in each age group as at 30 June 2000. The ratio of the male rate to the female rate is also shown in Table 2.

From Table 2 it can be seen that about 11 in 1,000 children, or just over one per cent of children, in NSW were being treated with stimulant medication for ADHD as at 1 December 2000. The rate was highest for children in the age group 9-11 years (19.3 per 1,000 resident population), followed by those in the age group 7-8 years (15.5 per 1,000 resident population). Children aged less than four years had the lowest rate at 0.2 per 1,000 resident population, followed by four year olds (1.7 per 1,000 resident population).

The rate for boys was about four times the rate for girls. As noted earlier, the largest discrepancy between the sexes was among children aged less than four years. In this age group the rate for boys was more than seven times the rate for girls.

Figure 9 shows the rate of children treated with stimulant medication for ADHD as at 1

\section{TABLE 1}

Number and percentage of children treated with stimulant medication for ADHD as at I December 2000 by age and sex

\begin{tabular}{|c|c|c|c|c|c|c|c|}
\hline \multirow[t]{2}{*}{ Age } & \multicolumn{2}{|c|}{ Males } & \multicolumn{2}{|c|}{ Females } & \multicolumn{2}{|c|}{ Total } & \multirow{2}{*}{$\begin{array}{l}\text { Ratio } \\
\text { M / F }\end{array}$} \\
\hline & No. & $\%$ & No. & $\%$ & No. & $\%$ & \\
\hline 2 yrs & 0 & 0.0 & 0 & 0.0 & 0 & 0.0 & - \\
\hline 3 yrs & 23 & 0.2 & 3 & 0.1 & 26 & 0.2 & 7.7 \\
\hline 4 yrs & 120 & 0.9 & 28 & 1.0 & 148 & 0.9 & 4.3 \\
\hline 5-6 yrs & 951 & 7.3 & 236 & 8.1 & 1,187 & 7.5 & 4.0 \\
\hline $7-8$ yrs & 2,267 & 17.4 & 498 & 17.1 & 2,765 & 17.4 & 4.6 \\
\hline 9-II yrs & 4,201 & 32.3 & 964 & 33.0 & 5,165 & 32.4 & 4.4 \\
\hline $12-15$ yrs & 4,452 & 34.2 & 937 & 32.1 & 5,389 & 33.8 & 4.8 \\
\hline $16-17$ yrs & 993 & 7.6 & 254 & 8.7 & 1,247 & 7.8 & 3.9 \\
\hline Total & 13,007 & 100 & 2,920 & 100 & 15,927 & 100 & 4.5 \\
\hline
\end{tabular}

Source: Pharmaceutical Drugs of Addiction System, Pharmaceutical Services Branch, NSW Department of Health. 
Rate per I,000 NSW resident population of children treated with stimulant medication for ADHD as at I December 2000 by age and sex

\begin{tabular}{lcccc}
\hline Age & Males & Females & Total & Ratio M / F \\
\hline < 4 yrs & 0.3 & 0.04 & 0.2 & 7.3 \\
4 yrs & 2.7 & 0.7 & 1.7 & 4.1 \\
5-6 yrs & 10.5 & 2.7 & 6.7 & 3.8 \\
7-8 yrs & 24.8 & 5.8 & 15.5 & 4.3 \\
9-I I yrs & 30.6 & 7.4 & 19.3 & 4.1 \\
I 2-I 5 yrs & 24.8 & 5.5 & 15.4 & 4.5 \\
I6-I 7 yrs & 10.9 & 2.9 & 7.0 & 3.7 \\
Total & 18.0 & 4.2 & 11.3 & 4.2 \\
\hline & & & \\
NSW resident population based on Australian Bureau of Statistics preliminary estimates of population as at 30 \\
June 2000 (Catalogue no. 3201.0). \\
Pharmaceutical Drugs of Addiction System, Pharmaceutical Services Branch, NSW Department of Health.
\end{tabular}

\section{FIGURE 9}

Rate per I,000 NSW resident population of children treated with stimulant medication for ADHD as at I December 2000 by single year of age and sex

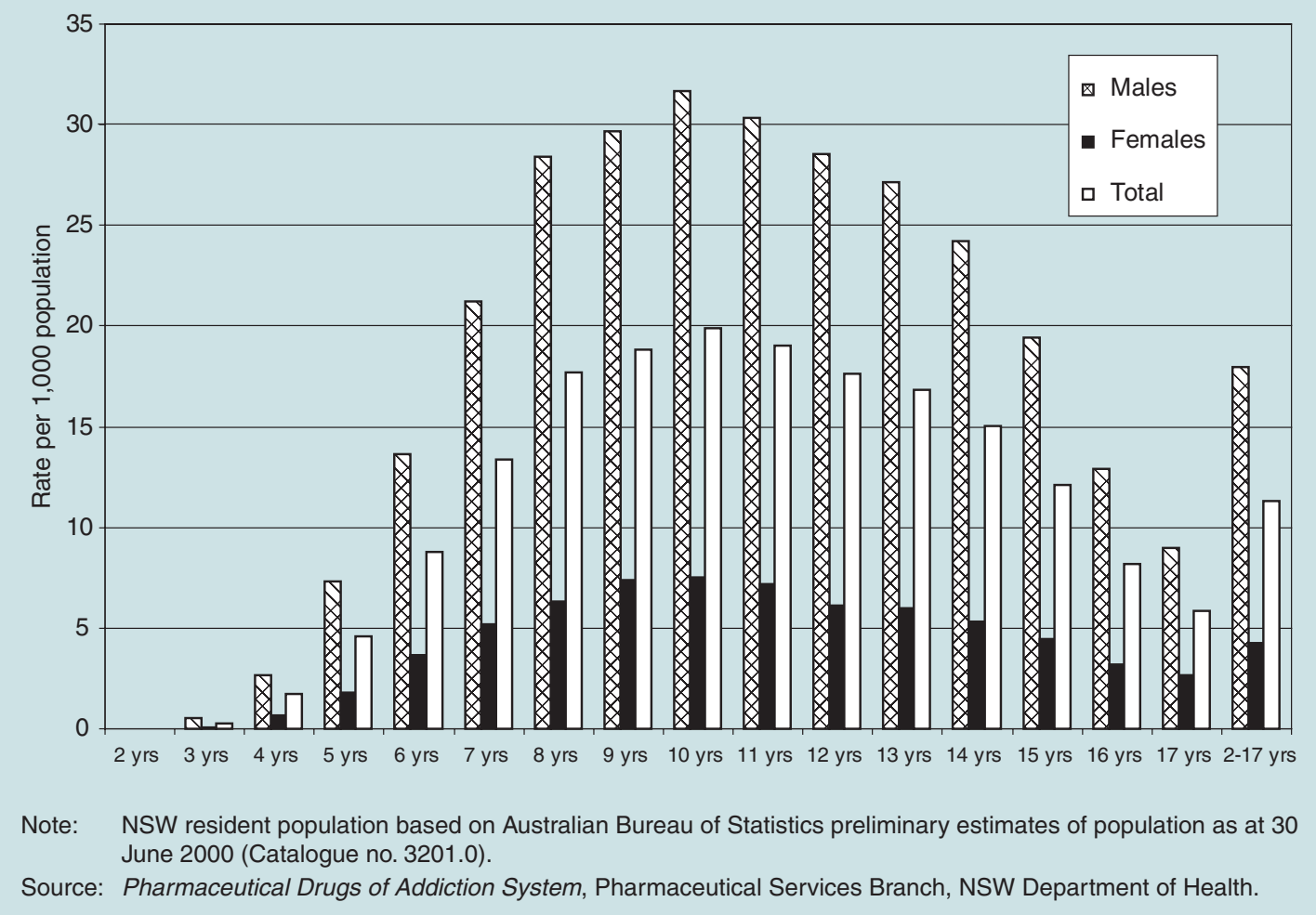


December 2000 by single year of age and sex. The rates for males and females overall (that is, all persons aged 2-17 years) are also shown in Figure 9.

For both boys and girls aged from seven to 15 years, the rate on stimulant medication was higher than the average. At a rate of 31.7 per 1,000 resident population, the rate for boys aged 10 years was about 1.8 times greater than the average for boys. The rate for girls of this age (7.5 per 1,000 resident population) was also 1.8 times the average for girls.

\subsubsection{Age and drug}

Figure 10 shows the percentage of children who were being treated with stimulant medication for ADHD as at 1 December 2000 according to the child's age and drug. It shows that a slightly higher proportion of children on stimulant treatment as at 1 December 2000 were on methylphenidate ( 52.0 per cent) than dexamphetamine (48.0 per cent).

These proportions differed slightly according to the child's age. The smallest proportion on methylphenidate ( 42.9 per cent) were children aged four years, while the highest proportion of children on methylphenidate (53.7 per cent) were 9-11 year olds.

\subsubsection{Age and dose}

Figure 11 shows the average daily dose (in tablets) for children treated with stimulant medication for ADHD as at 1 December 2000, according to the child's age and the drug. Children for whom the daily number of tablets prescribed could not be determined are excluded from Figure 11.

The average dose for methylphenidate was slightly less or the same as that for dexamphetamine, across all age groups. Figure 11 shows a positive association between age and dose; the greater the age, the higher the average daily dose (in tablets).

Figure 12 shows the percentage of children treated with stimulant medication for ADHD as at 1 December 2000, according to the child's age and the daily number of

\section{FIGURE 10}

Per cent of children treated with stimulant medication for ADHD as at I December 2000 by age and drug

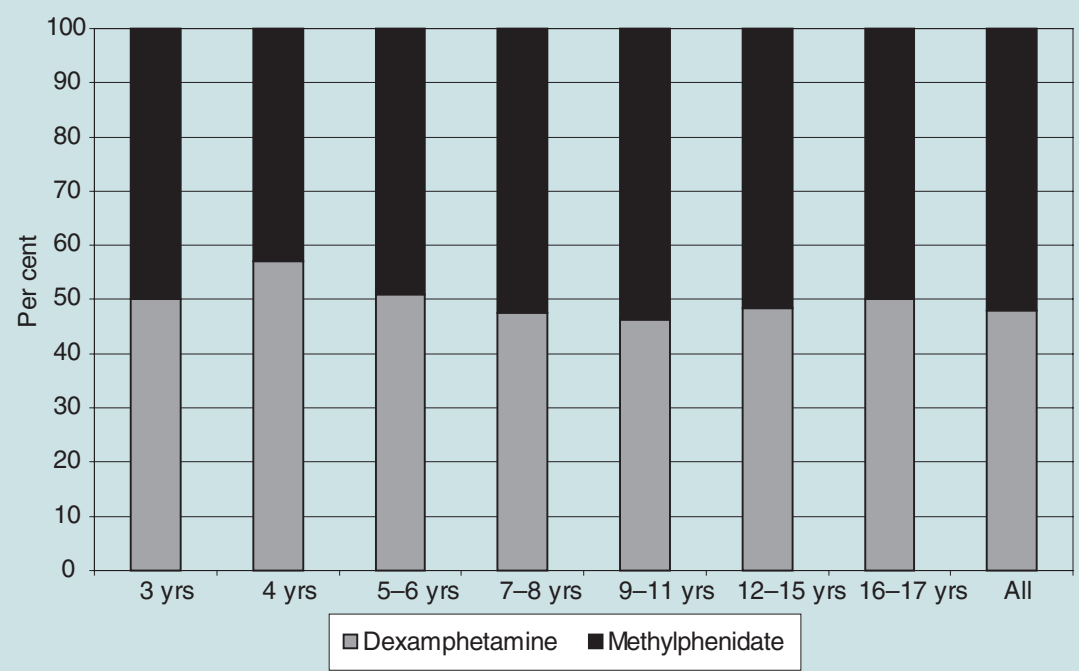

Note: Excludes 50 children for whom the drug of treatment could not be determined.

Source: Pharmaceutical Drugs of Addiction System, Pharmaceutical Services Branch, NSW Department of Health. 
Average daily dose (in tablets) for children treated with stimulant medication for ADHD as at I December 2000 by age and drug

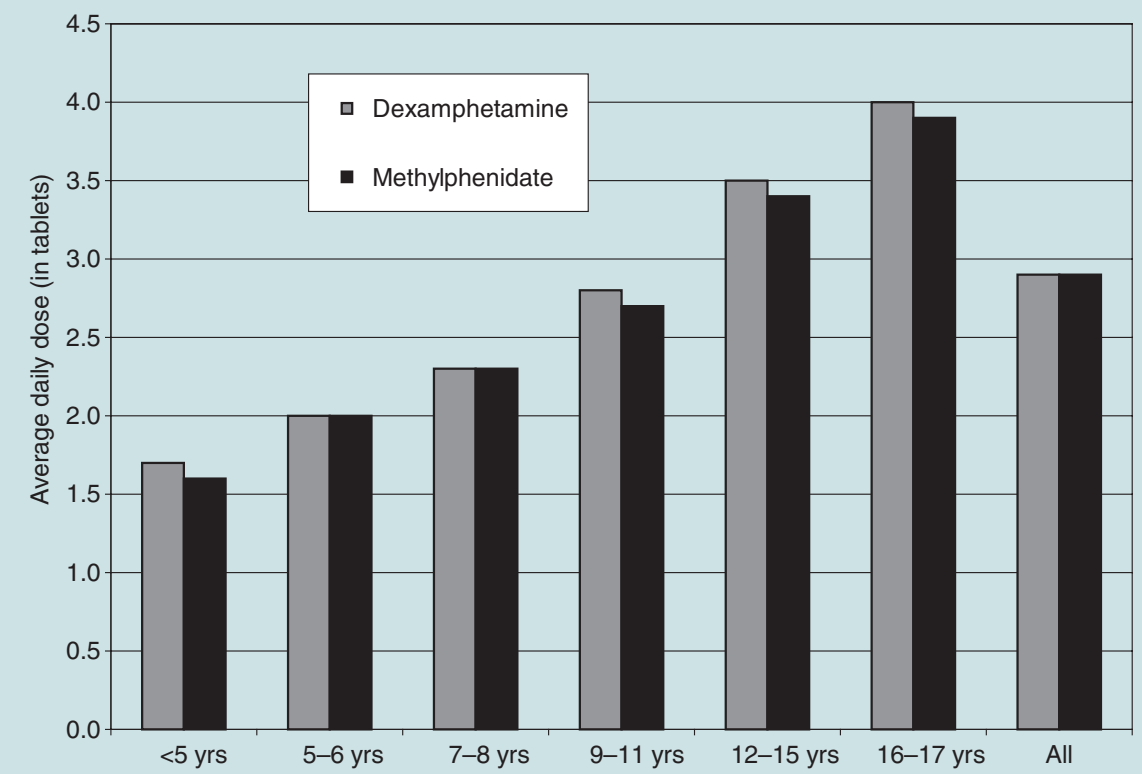

Note: Excludes 380 children for whom the daily dose could not be determined.

Source: Pharmaceutical Drugs of Addiction System, Pharmaceutical Services Branch, NSW Department of Health.

\section{FIGURE 12}

Per cent of children treated with stimulant medication for ADHD as at I December 2000 by age and daily dose

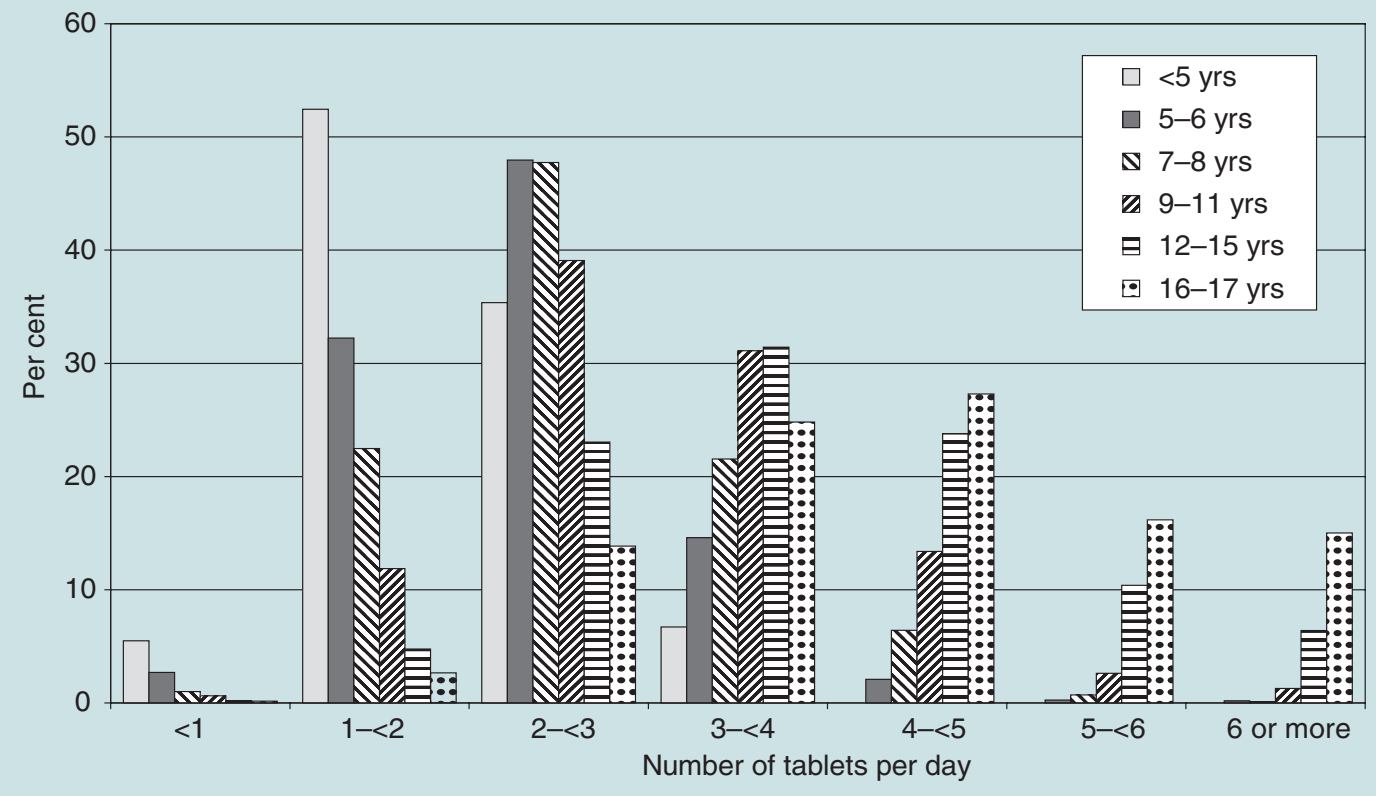

Note: Excludes 380 children for whom the daily dose could not be determined.

Source: Pharmaceutical Drugs of Addiction System, Pharmaceutical Services Branch, NSW Department of Health. 
tablets prescribed.

The relative frequency distributions for dexamphetamine and methylphenidate were very similar, hence data on the two drugs were combined. Children for whom the daily number of tablets prescribed could not be determined are excluded from Figure 12.

The positive association previously shown between age and dose is evident in Figure 12. A relatively high proportion of young children were on low doses, while older children were on higher doses. For example, the vast majority of children aged less than five years (93.3 per cent) were taking fewer than three tablets per day. In comparison, 83.3 per cent of those aged 16-17 years were taking three or more tablets per day.

\subsubsection{Health area of residence}

Figure 13 shows the rate (per 1,000 resident population) of children treated with stimulant medication for ADHD for each health area of residence as at 1 December 2000 by sex. The rate is based on the estimated number of children aged two to 17 years residing in each health area as at 30 June 1998.

The health areas that had the highest rate of children treated with stimulant medication for ADHD were, respectively, the Hunter, Central Coast, Mid North Coast, Macquarie, and Wentworth areas. Areas with the lowest rate, respectively, were the Far West, Central Sydney, South Western Sydney, Northern Rivers, and New England areas.

Figures 14 to 17 show the rate (per 1,000 resident population) of children treated with stimulant medication for ADHD for each health area of residence as at 1 December 2000 for the following age groups, respectively: 5-6 years, 7-11 years, 12-15 years and 16-17 years. The rates are based on the estimated number of children in each respective age group residing in each health area as at 30 June 1998. Areas are ordered according to the overall rate of treatment.

It can be seen that the differences in rates of treatment across areas seen in Figure 13 are generally reflected in Figures 14 to 17. The areas which had the highest rates of treatment overall had the highest rates of treatment in each age group. Children who had the highest rates of stimulant treatment were boys in the age groups 7-11 years and $12-15$ years who resided in the Hunter area. Almost one in 20 boys aged 7-11 years in the Hunter area were treated with stimulant medication for ADHD as at 1 December 2000. About one in 25 boys aged 12 to 15 years who resided in the Hunter area were treated with stimulant medication for ADHD as at 1 December 2000. These rates were 1.6 to 1.7 times the State average for these children.

Relative to the State average, the rate of treatment in the Northern Sydney area of boys and girls aged 16-17 years was high. About one in 53 boys aged 16-17 years (or 18.9 per 1,000 resident population) in the Northern Sydney area were treated with stimulant medication as at 1 December 2000. This rate is about 1.7 times the State average (11.1 per 1,000 resident population). For girls aged 16-17 years, the rate in the Northern Sydney area (5.0 per 1,000 resident population) was 1.7 times the State average (3.0 per 1,000 resident population).

\subsubsection{Duration of stimulant treatment}

Table 3 shows the continuous length of time on stimulant medication for children being treated with stimulants for ADHD as at 1 December 2000 by age.

Overall, about 40 per cent of children on stimulant medication as at 1 December 2000 had been on medication for up to a year. Just over three per cent (533 children) had been continuously on stimulant medication for more than seven years. The longest duration of continuous treatment was 12 years. Two children fell into this category; one commenced medication at about age five years, and the other commenced when he was aged about two-and-a-half years. 
Rate per I,000 NSW resident population of children treated with stimulant medication for ADHD as at I December 2000 by health area of residence and sex

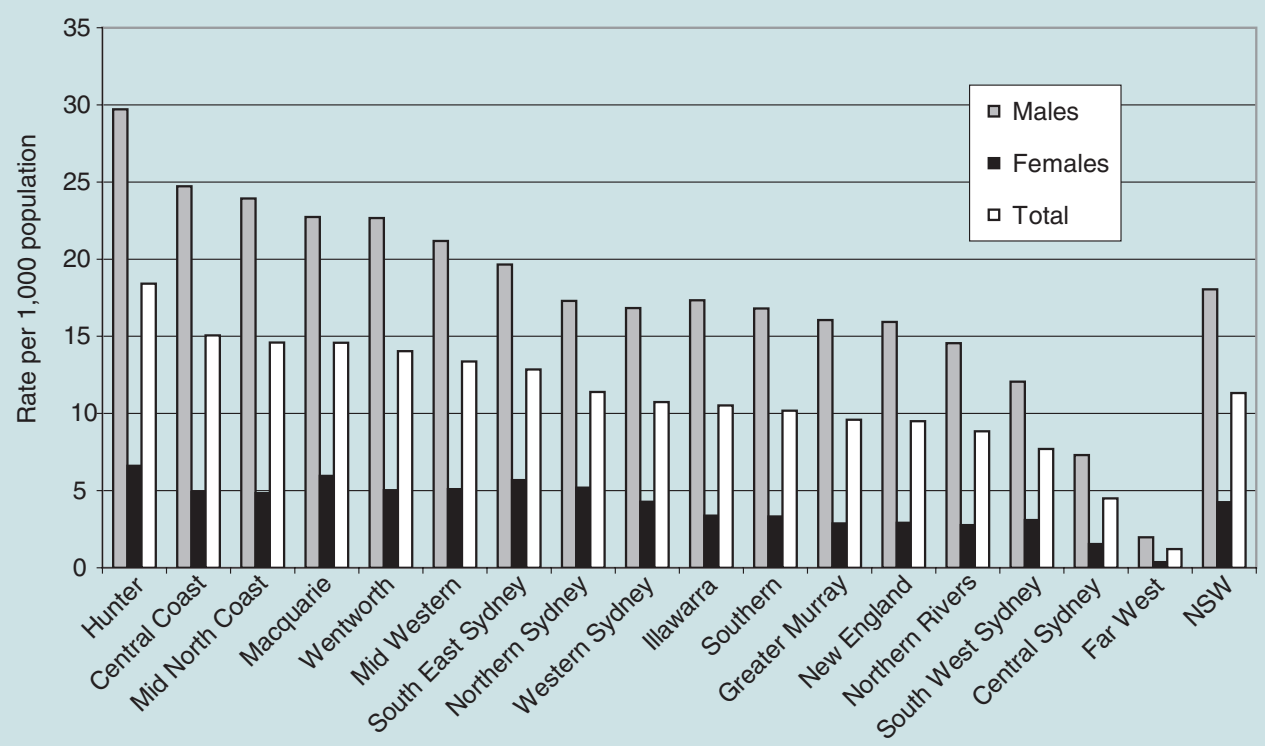

Notes: Excludes two children for whom health area of residence could not be determined.

Resident population based on Australian Bureau of Statistics estimates of population as at 30 June 1998 (unpublished data).

Source: Pharmaceutical Drugs of Addiction System, Pharmaceutical Services Branch, NSW Department of Health.

\section{FIGURE 14}

Rate per I,000 NSW resident population of children aged 5-6 years treated with stimulant medication for ADHD as at I December 2000 by health area of residence and sex

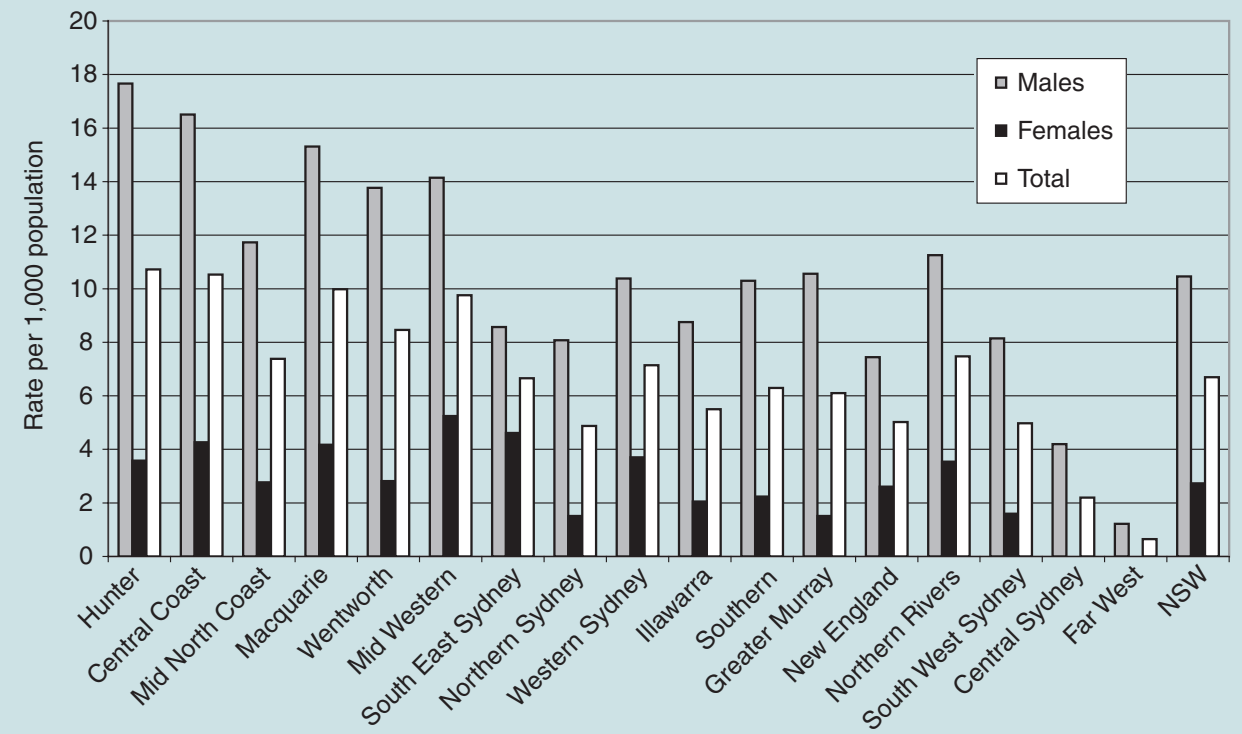

Notes: Resident population based on Australian Bureau of Statistics estimates of population as at 30 June 1998 (unpublished data).

Source: Pharmaceutical Drugs of Addiction System, Pharmaceutical Services Branch, NSW Department of Health. 


\section{FIGURE 15}

Rate per I,000 NSW resident population of children aged 7-I I years treated with stimulant medication for ADHD as at

I December 2000 by health area of residence and sex

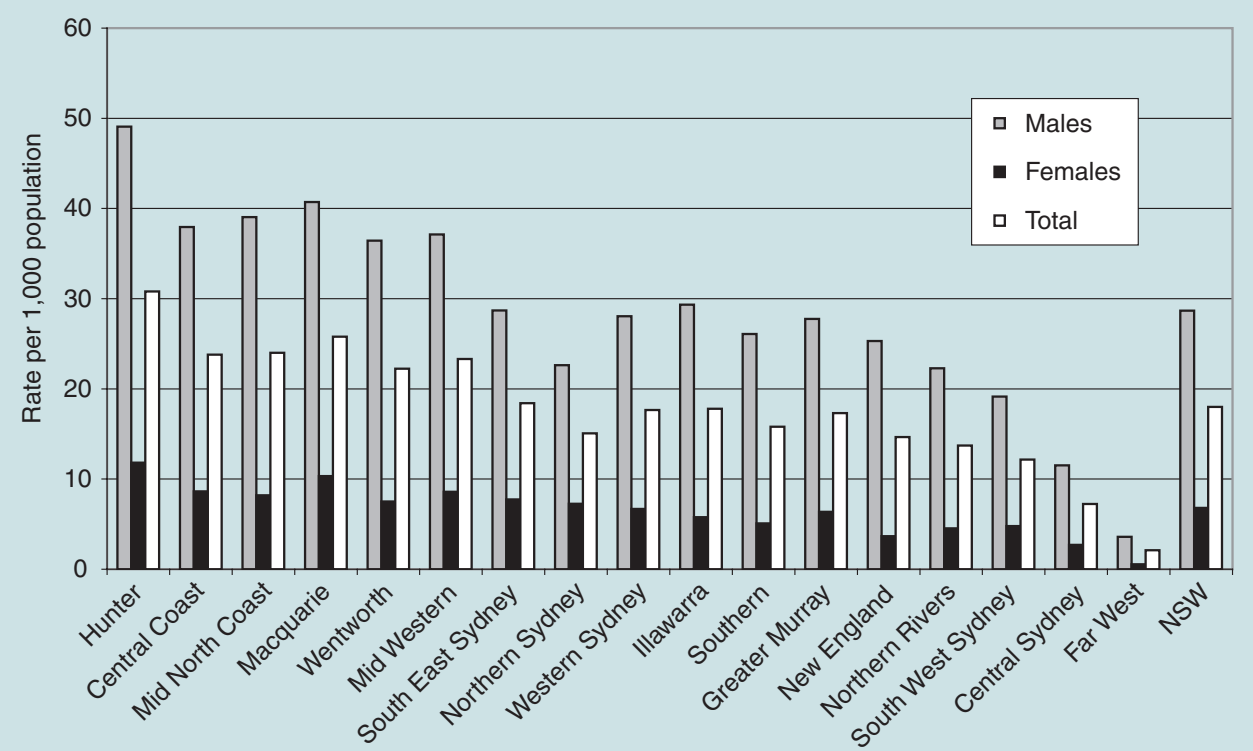

Notes: Resident population based on Australian Bureau of Statistics estimates of population as at 30 June 1998 (unpublished data).

Source: Pharmaceutical Drugs of Addiction System, Pharmaceutical Services Branch, NSW Department of Health.

\section{FIGURE 16}

Rate per I,000 NSW resident population of children aged I 2-I5 years treated with stimulant medication for ADHD as at

I December 2000 by health area of residence and sex

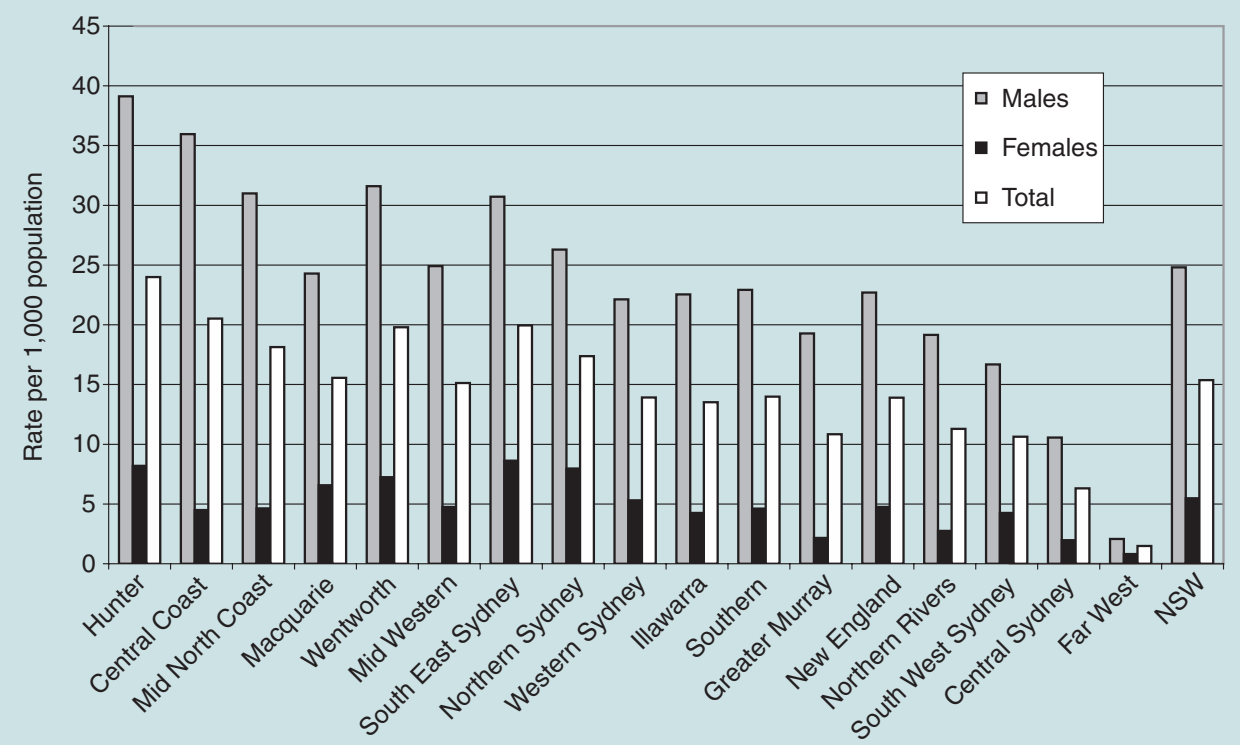

Notes: Resident population based on Australian Bureau of Statistics estimates of population as at 30 June 1998 (unpublished data).

Source: Pharmaceutical Drugs of Addiction System, Pharmaceutical Services Branch, NSW Department of Health. 


\section{FIGURE 17}

Rate per I,000 NSW resident population of children aged I6-I7 years treated with stimulant medication for ADHD as at I December 2000 by health area of residence and sex

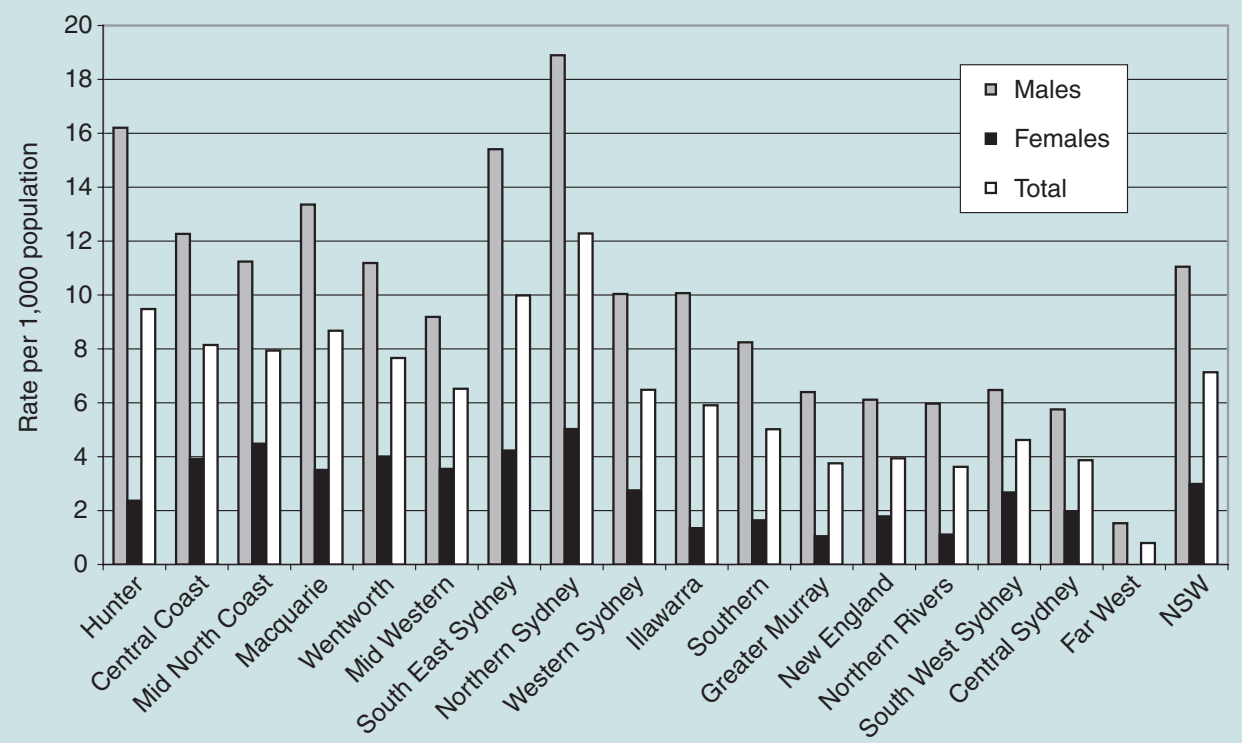

Notes: Resident population based on Australian Bureau of Statistics estimates of population as at 30 June 1998 (unpublished data).

Source: Pharmaceutical Drugs of Addiction System, Pharmaceutical Services Branch, NSW Department of Health.

age of the child. A higher proportion of older children were on medication for longer periods than younger children. For example, as at 1 December 2000, 40.4 per cent of children aged 16-17 years had been on medication for more than three years, while the comparable proportion of 7-8 year olds was 9.2 per cent. 


\section{TABLE 3}

Number and percentage of children treated with stimulant medication for ADHD as at I December 2000 by age and duration of continuous treatment

\begin{tabular}{|c|c|c|c|c|c|c|c|c|c|c|c|c|c|c|}
\hline \multirow{3}{*}{$\begin{array}{l}\text { Treatment } \\
\text { duration } \\
\text { (years) }\end{array}$} & & & \multicolumn{12}{|c|}{ Age } \\
\hline & \multicolumn{2}{|c|}{$<5$ yrs } & \multicolumn{2}{|c|}{ 5-6 yrs } & \multicolumn{2}{|c|}{$7-8$ yrs } & \multicolumn{2}{|c|}{ 9-II yrs } & \multicolumn{2}{|c|}{$12-15$ yrs } & \multicolumn{2}{|c|}{$16-17$ yrs } & \multicolumn{2}{|c|}{ Total } \\
\hline & Number & $r \%$ & Number & $r \%$ & Number & $\%$ & Number & $\%$ & Number & $r \%$ & Number & $r \%$ & Number & $\%$ \\
\hline$\leq \mathrm{I}$ & 154 & 88.5 & 825 & 69.5 & I,346 & 48.7 & 1,862 & 36.1 & I,736 & 32.2 & 422 & 33.8 & 6,345 & 39.8 \\
\hline$>1-2$ & 19 & 10.9 & 268 & 22.6 & 750 & 27.1 & I,095 & 21.2 & 928 & 17.2 & 181 & 14.5 & $3,24 I$ & 20.3 \\
\hline$>2-3$ & 1 & 0.6 & 78 & 6.6 & 415 & 15.0 & 875 & 16.9 & 705 & 13.1 & 140 & 11.2 & 2,214 & 13.9 \\
\hline$>3-5$ & 0 & 0.0 & 16 & 1.3 & 242 & 8.8 & 967 & 18.7 & 861 & 16.0 & 162 & 13.0 & 2,248 & 14.1 \\
\hline$>5-7$ & 0 & 0.0 & 0 & 0.0 & 12 & 0.4 & 346 & 6.7 & 817 & 15.2 & $17 \mid$ & 13.7 & 1,346 & 8.5 \\
\hline$>7-9$ & 0 & 0.0 & 0 & 0.0 & 0 & 0.0 & 20 & 0.4 & 321 & 6.0 & 125 & 10.0 & 466 & 2.9 \\
\hline$>9$ & 0 & 0.0 & 0 & 0.0 & 0 & 0.0 & 0 & 0.0 & 21 & 0.4 & 46 & 3.7 & 67 & 0.4 \\
\hline Total & 174 & 100 & $\mathrm{I}, 187$ & 100 & 2,765 & 100 & 5,165 & 100 & 5,389 & 100 & $\mathrm{I}, 247$ & 100 & 15,927 & 100 \\
\hline
\end{tabular}




\subsection{Section 4: Two- to three-year olds treated with stimulant medication}

In the period 1 January 1999 to 30 June 2000, individual patient authorities were issued for the first time in respect of 58 children aged less than four years. One of these children did not go on to take medication. Of the remaining 57 children, 48 were aged three years and nine were aged two years. The characteristics of these children are shown in Table 4. It should be noted that the characteristics presented in Table 4 are based on information supplied in medical reports by doctors treating the children. The actual prevalence of some characteristics may be higher than that indicated in Table 4. A child's failure to be included in the prevalence rate may not be because the child did not possess the characteristic but simply because the doctor did not provide the information in the medical report.

The majority of the children aged 2-3 years for whom an individual patient authority was first issued during the 18-month period 1 January 1999 to 30 June 2000 were male (86.0 per cent). A notable proportion of these young children (29.8 per cent) were reported as having some type of developmental delay, usually involving speech. In 15 cases (26.3 per cent) a relation of the child (for example: sister, brother, uncle) was reported to have ADHD. For most of the children, the age of onset of ADHD symptoms was reported. Among the three-year olds, age of onset of ADHD most commonly occurred before the age of two years.

\section{TABLE 4}

Characteristics of children aged 2-3 years

Initial authorities issued for stimulant medication for ADHD, I January 1999 to 30 June 2000

\begin{tabular}{l}
\hline Characteristics \\
\hline Male \\
Developmental delay \\
Familial ADHD \\
Age of onset \\
Dietary control \\
Behavioural-early intervention \\
Other medication, \\
(for example, clonidine) \\
Side effects from \\
stimulant medication
\end{tabular}

Effect of stimulant medication

Two-year olds
$n=9(\%)$
$8(88.9)$
$4(44.4)$
$5(55.6)$
$<$ I 2 months, $n=3(33.3)$
I $2-24$ months, $n=4(44.4)$
not reported, $n=2(22.2)$
$3(33.3)$
$3(33.3)$
$6(66.7)$
none, $n=3(33.3)$
at least one, $n=3(33.3)$
not reported, $n=3(33.3)$
improvement, $n=6(66.7)$
no improvement, $n=1(\mathrm{I}$ I.I)
not reported, $n=2(22.2)$

8 (88.9)

$4(44.4)$

Three-year olds

$n=48(\%)$

41 (85.4)

$13(27.1)$

$10(20.8)$

$<2$ years, $n=27(56.3)$

$\geq 2$ years, $n=18$ (37.5)

not reported, $n=3(6.3)$

4 (8.3)

13 (27.I)

18 (37.5)

none, $n=9(18.8)$

at least one, $n=19$ (39.6)

not reported, $n=20$ (4I.7)

substantial improvement,

$n=33$ (68.8)

some improvement,

$n=2$ (4.2)

no improvement, $n=I$ (2.I)

not reported, $n=12$ (25.0)

Source: Pharmaceutical Services Branch, NSW Department of Health 
Various treatments other than stimulant medication were reported. In about 28 per cent of cases some type of behavioural intervention or early intervention was attempted. A small proportion (12.3 per cent) had undergone some type of treatment involving diet. Non-stimulant medication was relatively common, with 42.1 per cent of the $2-3$ year olds having used this. The most common medication used was clonidine. In almost all cases, these other treatments were not helpful.

Almost four out of every ten children experienced a side effect of the stimulant medication. The most commonly reported concerned appetite, followed by emotional problems. Other side effects included sleeping problems, obsessive behaviours, stomach pain, rebound effects of the drug, thirst and headache.

For the majority of the children (71.9 per cent), stimulant treatment resulted in improvements in behaviour. Some children did not appear to respond positively to the medication, although there were no reports of behaviour worsening as a result of stimulant treatment.

Some individual cases are described below.

\section{Case I: ‘Michael', aged 2 years and 8 months}

Michael has a history of active, wilful and sometimes destructive behaviour. His mother reports that he has been very difficult from birth. She says she cannot take him anywhere and that no-one is prepared to mind him. He touches everything within sight, appears to have no fear, and does not learn from experience about what is dangerous, painful or forbidden. She says his play is not constructive and that he hurts other children. Michael does not respond to requests. Standard procedures such as timeout have not been effective; he destroys his surroundings.

Michael lives with his mother, who is separated from Michael's father. Michael's father was said to be very similar in temperament in early childhood, and as an adult has trouble concentrating. Michael has an older brother (from a different father) who is quiet and easygoing.

After unsuccessful family and individual counselling, treatment with dexamphetamine is commenced. Progress reports at one and three-months after commencing medication indicate that Michael's behaviour has considerably improved. His mother reports that he has become a pleasure to take shopping and that he can play constructively for long periods of time. The relationship between Michael and his mother has improved, as has her handling of his behaviour. Michael's grandparents and day carers have noticed the improvement. He continues to be fairly boisterous.

Treatment with dexamphetamine is discontinued after three months. Michael continues to do well at home and at day care. His mother is cheerful and enjoying the relationship with her son.

\section{Case 2: 'Phillip', aged 2 years and 8 months}

Phillip was noticed by his mother to have a very bad temper at eight months of age. By age 12 months it was clear that he was extremely hyperactive. A neighbour had offered to look after him on three occasions, but each time needed to return the boy to his mother because he was uncontrollable. He has been taken out of preschool because of antisocial behaviour. Phillip has a younger sister whom he hits and kicks.

Phillip's doctor describes his visit to his office as a 'disaster'. Phillip did not stay with multiple toys for more than two minutes and ripped up a number of books. He did not take notice of his mother's instructions.

Phillip's mother has language-based problems in reading and spelling, as well as two 
cousins with ADHD. Phillip's father claims to have had difficulties with concentration and organisation at school, and in adolescence had some symptoms of conduct disorder.

Various interventions, including a restrictive diet, parenting skills training and behaviour management, have been tried without benefit. Phillip is prescribed dexamphetamine. According to a progress report seven weeks into treatment, Phillip's parents have noticed a dramatic improvement in his behaviour. He is much less hyperactive, and much more attentive and responsive to their instructions. In the initial stages of treatment he is quite teary on a few occasions but this side effect resolves itself. His appetite is also initially affected but returns to normal.

A progress report at three months into treatment states that the effects of the medication in the dose given are reduced. Phillip's behaviour is perhaps marginally better than it was before stimulant medication was commenced. Phillip's mother continues to try behaviour modification strategies, such as timeout, but Phillip remains defiant, smashing toys and furniture. She is becoming overwhelmed by his behaviour. A change in dosing is suggested, as well as a dose of clonidine.

At almost three-and-a-half years of age, Phillip is attending preschool a few days a week, but his behaviour at home is extremely difficult. Occasionally when he wakes in the middle of the night he goes about the house wreaking havoc. A period of residential observation is suggested to the parents. A higher dose of stimulant medication, or use of other medications are considered.

\section{Case 3: 'Kylie', aged 2 years and 7 months}

Kylie has always been an active child. She finds it difficult to sit still and is unable to watch television. Kylie displays oppositional behaviour towards her mother. She has temper tantrums when she doesn't get her own way and is violent towards her younger brother. She is a poor and restless sleeper, often not getting to sleep until 11.00 p.m. in the evening.

Developmentally, Kylie is progressing normally. There do not appear to be any dietary triggers to her behaviour; her mother avoids giving her cordial and lollies.

Three of Kylie's cousins are being treated for ADHD. Her older sister does not pose any behavioural or educational problems. Her younger brother is copying her behaviour and this concerns Kylie's mother. Kylie's father has no difficulty with reading but her mother does occasionally. Because of his work, Kylie's father spends significant time away from home. Her mother is becoming increasingly negative toward Kylie because of her hyperactivity, disruptiveness and lack of response to parental intervention.

Dexamphetamine is prescribed. According to a progress report two months into treatment, Kylie is responding well. There has been a significant improvement in her level of activity, irritability, and communication at home and preschool. She is much better able to stay on task. Some days she does not require medication. Her mother finds her much easier to discipline. Kylie is not experiencing any side effects.

Eight months after medication is commenced, the improvements are maintained. When there is lessened stimuli in Kylie's environment she does not require medication. Her mother is anxious not to overuse medication.

\section{Case 4: 'Harry', aged 3 years and 7 months}

Harry is a boy who is continually on the go. He is prone to tantrums and often shows aggression (hitting, kicking, biting) towards his parents and younger sister. His parents 
fear taking him out in public because he hits out and yells at strangers. He has been having night terrors most nights for over a year. Harry gets very upset when his routine is disturbed.

He is described by his preschool as a complex and difficult child to manage. He tends to be a loner at preschool. He tantrums at preschool and his mother has had to collect him on a few occasions.

Harry is not toilet trained. He has moderately severe language delay, as well as immature play and social skills.

Harry's parents find his behaviour upsetting. They are finding him hard to cope with. Harry's grandparents are concerned for him and his family. They mind Harry occasionally, as a form of respite care for his parents.

According to Harry's grandmother, his mother was overactive as a child. Harry's father indicates he had delayed speech development as a child.

Harry has been involved with an early intervention program but this was discontinued recently. He has not been able to be assessed by a speech therapist because of his disruptive behaviour.

Dexamphetamine is prescribed with positive results. A progress report at four weeks indicates he is less active and seems to concentrate better at tasks. His aggressive behaviours have diminished and he is playing more co-operatively with his sister. His tantrums have also diminished and he is more compliant with instructions.

On medication, his sleep pattern has generally changed for the better, although he occasionally does not get to sleep until after 11.00 p.m. He has lost some weight since beginning medication, and developed some mild obsessional behaviour about cleanliness.

Re-commencement of the early intervention program is recommended, as well as ongoing speech therapy.

After two months on medication, Harry's positive response to medication is maintained. He is experiencing no significant side effects.

\section{Case 5: 'Daniel', aged 3 years and 8 months}

Daniel is a large boy who is constantly on the move until late into the night. He has no patience to play with a toy or watch a cartoon. He is oppositional and defiant and will throw a tantrum if he cannot get his own way.

The carers at his preschool have difficulty coping with him. He is extremely energetic. He displays aggressive and impulsive behaviour; he hits out, swears and spits at carers and other children. He is exceptionally strong and can be a danger to others as he tips over and throws furniture.

Daniel has been assessed as having delayed language.

Daniel lives with his mother. She indicates no family history of ADHD or learning difficulties.

Daniel is commenced on dexamphetamine. He responds well in the first month but in the second month the effects appear to wear off rapidly. He is more quiet and tractable on medication.

According to a progress report about six months into treatment, Daniel is described as being extremely hyperactive and impossible to manage without medication. 
Eleven months after commencing medication, Daniel has made significant progress. Behavioural strategies and counselling for both Daniel and his mother are being used. Daniel is attending a school and improving his academic and social abilities. He is not experiencing any side effects from the medication.

\section{Case 6: 'Peter', aged 3 years and I month}

Peter is a relentlessly over active boy who has tempter tantrums when limits are set on him. He pulls his hair out. He is more settled with one-to-one attention. He has been very active since he began walking at age 10 months. He likes to climb and has climbed over six-foot fences. On one occasion he set fires in his home. His speech is slightly immature for his age.

At preschool he has difficulty settling to play and forming relationships because he moves so quickly from one thing to the next. He is not particularly aggressive. $\mathrm{He}$ is affectionate with the carers.

Peter's father is described as being very similar to Peter at a similar age. He went on to have problems with academic failure, conduct disorder, and substance abuse. Peter no longer has contact with his father. Peter has an older sister being treated with stimulant medication for ADHD.

Peter's mother has been prone to depression and anxiety. She is getting significant benefit from attending a parenting course. She receives regular respite care through a charity organisation.

Methylphenidate is prescribed for Peter. According to a progress report around four-anda-half months into treatment, Peter has shown moderate but significant improvement in his impulsivity and ability to focus. His behaviour is also settled at preschool. His speech also appears to have improved. He has experienced some appetite suppression on medication, but has no other side effects. 


\subsection{Section 5: Attrition from stimulant treatment}

Table 5 examines attrition from stimulant treatment. It shows the number of children in 1997 who started on stimulant medication for the first time when aged three to 15 years, according to the time between the first and last prescription. The table does not include any children for whom an individual patient authority had ever been issued.

Table 5 shows that about 19 per cent of children aged 3-15 years who started on stimulant medication in 1997 did not continue medication after their first prescription. This proportion was roughly the same for children commenced on dexamphetamine (19.9 per cent) and for children commenced on methylphenidate (18.1 per cent). For over one-third of the children, the time between the first and last prescription was no more than 12 months.

The pattern seen in Table 5 was similar for most children. However, as shown in Figure 18 , it was quite different for some.

Figure 18 shows the percentage of children who discontinued stimulant treatment after one prescription, by age, for children aged 3-15 years who first started treatment in 1997.

For children aged five, six and seven years, the proportion who discontinued treatment with stimulant medication after the first prescription was 14.4 per cent, 13.1 per cent and 14.8 per cent, respectively. In contrast, for children aged 14 and 15 years, the percentage who discontinued treatment with stimulant medication after the first prescription was 35.9 per cent and 39.8 per cent, respectively.

\section{TABLE 5}

Number of children first started on stimulant medication in 1997 when aged 3-15 years by time between first and last prescription

\begin{tabular}{|lrcc|}
\hline Time between first and last prescription & Number & Per cent & $\begin{array}{l}\text { Cumulative } \\
\text { per cent }\end{array}$ \\
\hline O months & & & \\
(that is, first prescription = last prescription) & 908 & 19.2 & 19.2 \\
SI month & 55 & 1.2 & 20.4 \\
>I-6 months & 300 & 6.4 & 26.7 \\
>6-12 months & 368 & 7.8 & 34.5 \\
>I 2 months & 3,091 & 65.5 & 100 \\
Total & 4,722 & & \\
\hline
\end{tabular}

Source: Pharmaceutical Drugs of Addiction System, Pharmaceutical Services Branch, NSW Department of Health. 


\section{FIGURE 18}

Per cent of children (aged 3-I5 years who were first treated in 1997) who discontinued treatment after one prescription, by age

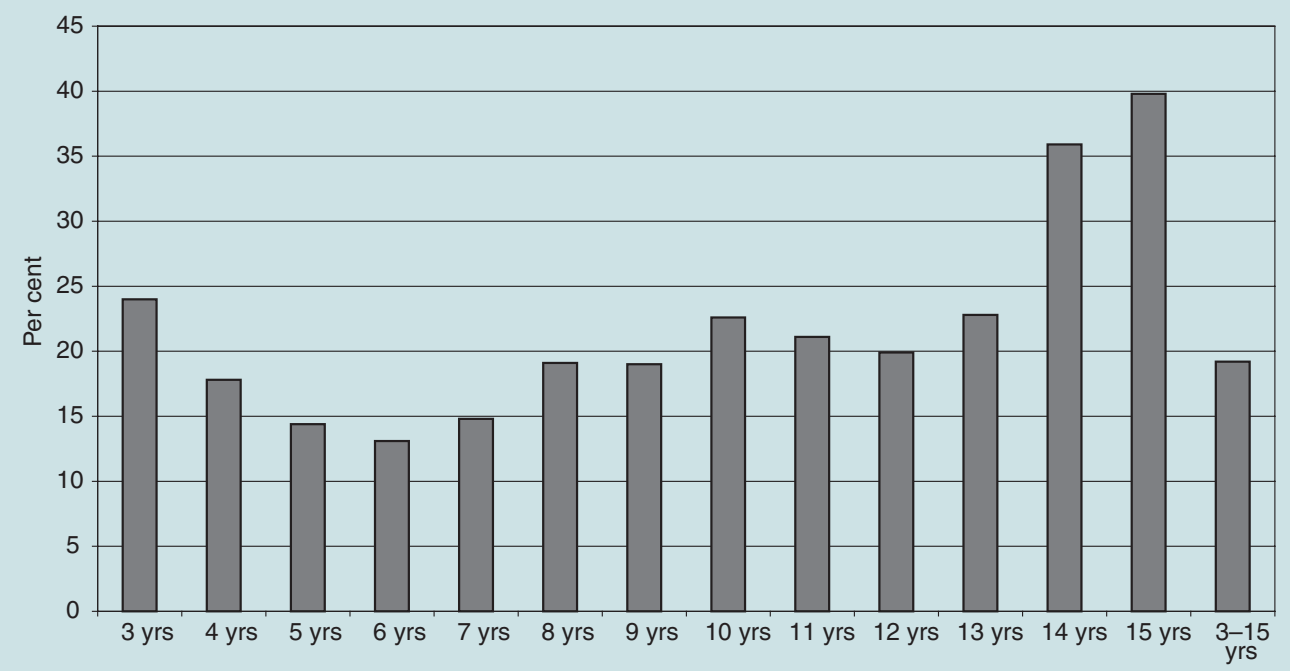

Source: Pharmaceutical Drugs of Addiction System, Pharmaceutical Services Branch, NSW Department of Health. 